\title{
Dose-Related Suppression of REM Sleep and PGO Waves by the Serotonin-1 Agonist Eltoprazine
}

James J. Quattrochi, Ph.D., Adam N. Mamelak, M.D., Devin Binder, B.S., Julie Williams, B.S., and J. Allan Hobson, M.D.

Parenteral administration of the serotonin-1 agonist eltoprazine $(0.0625$ to $4.0 \mathrm{mg} / \mathrm{kg}[0.0002$ to 0.016 $\mathrm{mmol} / \mathrm{kg}]$ ) in freely moving cats produced significant suppression of electrophysiologic rapid eye movement (REM) sleep signs, ponto-geniculo-occipital (PGO) activity, and REM sleep behavior. The virtual total suppression of REM sleep $(0.4 \%, 4.0 \mathrm{mg} / \mathrm{kg})$ and PGO wave activity (2 to $4 \mathrm{mg} / \mathrm{kg}$ ) in exchange for increasing amounts of non-REM (NREM) slow-wave sleep was a dose-dependent function of the amount of eltoprazine administered. Wakefulness was unaffected by eltoprazine regardless of dose. Concurrent with this dose-dependent suppression of REM was a dose-dependent increase in electroencephalographic synchrony and mean electromyographic amplitude. Since eltoprazine was found to shift the balance between REM and NREM sleep but did not change the balance between sleep and waking, it is a potentially useful tool for the investigation of serotonergic-cholinergic interaction.

[Neuropsychopharmacology 8:7-13, 1993]
KEY WORDS: REM sleep; PGO waves; Serotonin; Eltoprazine

Despite the large number of studies implicating serotonin $(5-\mathrm{HT})$ in the modulation of behavioral state, its exact role in the regulation of sleep and waking remains unclear. Pharmacological studies designed to elucidate the mechanism by which 5-HT neurotransmission affects behavioral state have reported paradoxical or contradictory results. While the listing of multiple 5-HT receptor subtypes (Glennon 1986; Peroutka 1988) has elucidated many of the pharmacological properties of serotonin and underscores the complexity of its modulatory influences, this research has failed to provide a detailed understanding of behavioral state control and

From the Laboratory of Neurophysiology, Harvard Medical School, Boston, Massachusetts.

Address correspondence to James J. Quattrochi, Ph.D. Laboratory of Neurophysiology, Harvard Medical School, 74 Fenwood, Boston, MA 02115.

Received September 27, 1991; revised January 15, 1992; accepted January 18, 1992. neurophysiological phenomena. One reason for this failure is that surprisingly few studies have focused on how administration of receptor-specific 5-HT agonists affects sleep, particularly rapid eye movement (REM) sleep.

We have previously observed suppression of REM sleep by the parenteral administration of the $5-\mathrm{HT}_{1}$ agonist eltoprazine (Quattrochi et al. 1990) and documented the REM rebound that followed discontinuation of the drug. These findings support the hypothesis that REM sleep is under the inhibitory control of serotonin (Hobson and Steriade 1986). We now demonstrate that the suppression of REM sleep is dose dependent and show that the dose-response properties of one relatively specific REM sleep sign, pontogeniculo-occipital (PGO) waves, are quantitatively sensitive to eltoprazine.

PGO waves are of particular interest because they are highly specific phenomena of REM sleep. Early studies by Jouvet (1969), Delorme et al. (1965), and Dement et al. (1973) indicated that PGO activity was susceptible to serotonergic inhibition; successive studies 
have reemphasized this association. The limitation of these studies is that they used drugs that influenced serotonergic neurons indirectly or nonspecifically. PGO waves are now known to be generated by PGO burst cells (Sakai 1980) located within the region of the cholinergic/peribrachial pontine tegmentum (Steriade et al. 1990a), and continuous PGO wave activity independent of REM has been described by Vivaldi et al. (1980) following microinjection of the cholinergic agonist carbachol into this peribrachial region. In our study, we observed a significant dose-dependent suppression of PGO activity during eltoprazine administration. This finding supports the hypothesis that the cholinergic/PGO burst cell network is particularly sensitive to serotonergic inhibitory control.

Eltoprazine is a recently developed phenylpiperazine derivative classified as a selective $5-\mathrm{HT}_{1}$ ligand (Raghoebar et al. 1990). Neurochemical studies provide evidence that the pharmacological actions of eltoprazine in vivo are attributable to interaction with the $5-\mathrm{HT}$ system via specific agonist action on $5-\mathrm{HT}_{1 \mathrm{~A}}$ and $5-\mathrm{HT}_{1 \mathrm{~B}}$ receptors (Raghoebar et al. 1990). We now report the results of a dose-response study of the role of eltoprazine in controlling sleep. We demonstrate that the electrophysiological features of sleep are differentially affected by eltoprazine and that overall suppression of REM in exchange for increasing amounts of non-REM (NREM) slow-wave (S) sleep is a dose-related function of the amount of eltoprazine administered. The doseresponse profile of eltoprazine that we have established allows us to clarify and more confidently interpret its pharmacological effects, since they indicate that the suppression of REM sleep and PGO activity are directly attributable to the serotonergic agonist action of the drug. The effects of eltoprazine on a known cholinergic REM sleep state may contribute to the behavioral profile of eltoprazine.

\section{METHODS}

\section{Animal Preparation}

Stereotaxic implantation of chronic recording electrodes was performed with pentobarbital sodium ( $35 \mathrm{mg} / \mathrm{kg}$ ) anesthesia administered IP to four adult male cats weighing 3.5 to $5.0 \mathrm{~kg}$. Placement of insulated tungsten wire electrodes permitted recording of cortical electroencephalograms (EEG), nuchal electromyograms (EMG), posteriororbital electrooculograms and bilateral lateral geniculate bodies for measurement of PGO wave activity. These procedures are described in detail elsewhere (Quattrochi et al. 1989). Animals were allowed to recover for 10 to 14 days after surgery before beginning control recordings.

\section{Pharmacological Protocol}

Eltoprazine (1-[2,3-dihydro-1,4-benzodioxin-5-yl]piparazine, DU28853, Duphar B.V.) is reported to demonstrate high affinity to $5-\mathrm{HT}_{1 \mathrm{~A}}\left(\mathrm{~K}_{\mathrm{i}}=40 \mathrm{nmol} / \mathrm{L}\right)$ and $5-\mathrm{HT}_{1 \mathrm{~B}}\left(\mathrm{~K}_{\mathrm{i}}=52 \mathrm{nmol} / \mathrm{L}\right)$ receptor subtypes (Raghoebar et al. 1990). Affinity toward other neurotransmitter receptors such as $5-\mathrm{HT}_{2,3}, \alpha_{1,2}, \beta_{1,2}, \mathrm{D}_{1,2}$, and $\mathrm{M}_{1,2,3}$ is significantly lower $\left(K_{i}>400 \mathrm{nmol} / \mathrm{L}\right)$. A semilogarithmic dosage schedule was used. All injections were performed IP in a total injection volume of $2 \mathrm{cc}$ sterile saline and administered each day at 11:00 A.M. Control injections consisted of saline. Eltoprazine was administered on the day after control recordings were performed; a washout period of five days followed. The dose-response curve was generated by the following dose amounts of eltoprazine: $0.0625,0.125,0.25,0.5$, $1.0,2.0$, and $4.0 \mathrm{mg} / \mathrm{kg}(0.0002,0.0005,0.001,0.002$, $0.004,0.008$, and $0.016 \mathrm{mmol} / \mathrm{kg}$ ). Each dose was administered among cats in a balanced order (low to high $[n=2]$; high to low $[n=2])$.

\section{Recording of Behavioral State}

Electroencephalogram recordings were performed continuously for 22 hours on unrestrained cats using Grass model 810 and model 6 electroencephalographs. All trials were conducted in a recording cage $(4 \times 2 \times 2$ feet) under constant illumination. Food and water were provided ad lib. During the two unrecorded hours (9:00 A.M. to 11:00 A.M.) each day, cats were kept awake while being fed, exercised, and cared for in an adjacent animal room.

\section{Data Acquisition}

Polygraphic data were collected by our automated data acquisition system (DAS) as previously described (Mamelak et al. 1991). Four wavebands were monitored: delta ( 1 to $4 \mathrm{~Hz}$ ), spindle ( 5 to $14 \mathrm{~Hz}$ burst of 3 or more waves), PGO (4 to $14 \mathrm{~Hz}$, monophasic) and EMG (amplitude units). Using the DAS, we acquired continuous quantitative measures of electrographic parameters for each control and dose condition in all four cats and stored these data for quantitative analysis.

\section{Quantitative Analysis of Waveband Counts}

Behavioral state was determined by computer scoring all sleep recordings in 15 -second bins using a previously described neural network program (Mamelak et al. 1991) and spot checking hand scoring of selected records. Waveband counts were quantified and analyzed by dose and cat. Three wavebands were quantified-delta, PGO, and EMG amplitude. Since both be- 
havioral state percentage and waveband parameters demonstrated similar trends for all cats, we restricted our detailed quantitative analysis of waveband counts to one cat. Data from counts in consecutive 1 minute epochs were summed into hourly count totals and then subjected to multivariate analysis of variance. Dose and hour effects were investigated. Post hoc Scheffe and Bonferroni $t$ tests $(p<0.05)$ were performed to determine if variability between condition was attributable to intrinsic variation among cats. All statistical analyses were performed on a mainframe computer using SAS statistical analysis software (SAS Institute).

\section{RESULTS}

Results were compiled from a total of 56 IP injections in cats. Table 1 presents mean values of all behavioral state parameters by dose obtained from 28 eltoprazine and 28 saline injections.

\section{Behavioral State Changes}

Total percent of time per 22-hour recording period spent in REM (REM\%) decreased in a dose-dependent manner from a control mean of $14.4 \pm 0.4 \%$ to a mean of $0.4 \pm 0.4 \%$ at $4 \mathrm{mg} / \mathrm{kg}$ eltoprazine $(F=19.11, p<0.001)$. Figure $1 \mathrm{~A}$ illustrates this dose-related decrease in REM\%. The REM\% did not vary significantly among cats $(F=1.5, p>0.20)$.

Rapid eye movement latency showed a dosedependent increase from a control mean of $62.2 \pm 5.0$ minutes to a $4.0-\mathrm{mg} / \mathrm{kg}$ dose mean of over 22 hours (Fig. $1 B)$. This increase in REM latency was markedly dose dependent and significant $(F=311.17, p<0.001)$, and did not vary significantly among cats $(F=0.03, p>0.5)$. The dose-dependent lengthening of REM latency inversely parallels the decrease in REM\%.

Conversely, total time spent in S sleep (S\%) showed a dose-dependent increase from a control value of 45.7 $\pm 2.1 \%$ to a mean of $58.7 \pm 8.5 \%$ at a dose of $4 \mathrm{mg} / \mathrm{kg}$ eltoprazine ( $F=15.20, p<0.001$; Fig. $1 C)$. However, this dose-related increase in $S \%$ varied by cat $(F=22.42$, $p<0.001)$; most of the variability was shown by one cat, which also differed in total time spent awake (W\%).

Total time awake was the only behavioral state parameter that did not vary by dose. Mean W\% under control conditions was $37.8 \pm 2.2 \%$ and at the $4.0-\mathrm{mg} / \mathrm{kg}$ dose was $40.9 \pm 8.1 \%$, with no significant variation with dose demonstrated $(F=0.08, p>0.5$; Fig. $1 D)$. This parameter varied by cat $(F=19.35, p<0.001)$, with variability confirmed to be attributable to one cat having a lower W\% and correspondingly higher $\mathrm{S} \%$ than the other cats. Despite these intercat differences in $\mathrm{W} \%$ and $\mathrm{S} \%$, mean values of $\mathrm{W} \%$ were found to be unchanged regardless of dose for each cat $(p>0.05)$.

\section{Electrographic Waveband Changes}

Table 2 summarizes the polygraphic parameters measured by the computer-based DAS and compared for each dose. The number of PGO waves counted by DAS was observed to be a markedly dose-dependent electrographic feature of behavioral state $(F=127.53, p<$ $0.001)$, ranging from a control value of $968 \pm 49$ counts per hour to a mean of $19 \pm 7$ at $4 \mathrm{mg} / \mathrm{kg}$ eltoprazine (Fig. 2, top). PGO wave counts were not observed to be significantly different by hour $(F=1.21, p>0.25)$.

A dose-dependent increase in delta wave counts was observed at the highest dose ( $4 \mathrm{mg} / \mathrm{kg}$ eltoprazine) with a mean of $4465 \pm 207$ counts per hour compared with a control value of $2345 \pm 74(F=342.73, p<0.001$; Fig. 2, middle). Delta wave counts were also shown to be significantly different by hour $(F=11.39, p<0.001)$. However, a significant difference in $F$ values confirmed that mean variability was attributable to dose $(F=$ 342.73). No statistically significant increase in delta wave counts was found at doses less than $4 \mathrm{mg} / \mathrm{kg}$ eltoprazine.

Mean EMG amplitude also increased with increasing doses of eltoprazine from a control value of 1858

Table 1. Behavioral State Parameters by Dose

\begin{tabular}{lccccc}
\hline $\begin{array}{l}\text { Dose } \\
\text { (mg/kg) }\end{array}$ & W\% & S\% & SP\% & REM\% & REM latency \\
\hline Saline & $37.8(2.2)$ & $45.7(2.1)$ & $4.1(0.3)$ & $14.4(0.4)$ & $62.2(5.0)$ \\
0.0625 & $48.3(6.2)$ & $38.9(6.0)$ & $3.6(1.0)$ & $11.1(0.8)$ & $153.2(47.6)$ \\
0.125 & $49.1(5.8)$ & $39.7(5.6)$ & $2.2(0.6)$ & $10.1(0.3)$ & $251.1(76.5)$ \\
0.25 & $60.0(9.4)$ & $39.3(7.5)$ & $1.1(1.1)$ & $9.3(1.6)$ & $390.0(120.5)$ \\
0.5 & $52.5(8.4)$ & $38.5(9.0)$ & $1.0(0.7)$ & $8.6(1.0)$ & $499.3(27.2)$ \\
1.0 & $45.2(7.2)$ & $48.6(7.6)$ & $1.4(0.1)$ & $5.0(1.2)$ & $733.1(22.8)$ \\
2.0 & $44.9(7.4)$ & $53.1(8.8)$ & $0.3(0.0)$ & $2.1(1.5)$ & $1006.5(108.4)$ \\
4.0 & $40.9(8.1)$ & $58.7(8.5)$ & $0.0(0.0)$ & $0.4(0.4)$ & $>22$ hours \\
\hline
\end{tabular}

Values expressed as mean (SEM) for 28 (saline) and 4 (each dose) injections. REM latency expressed in minutes. 

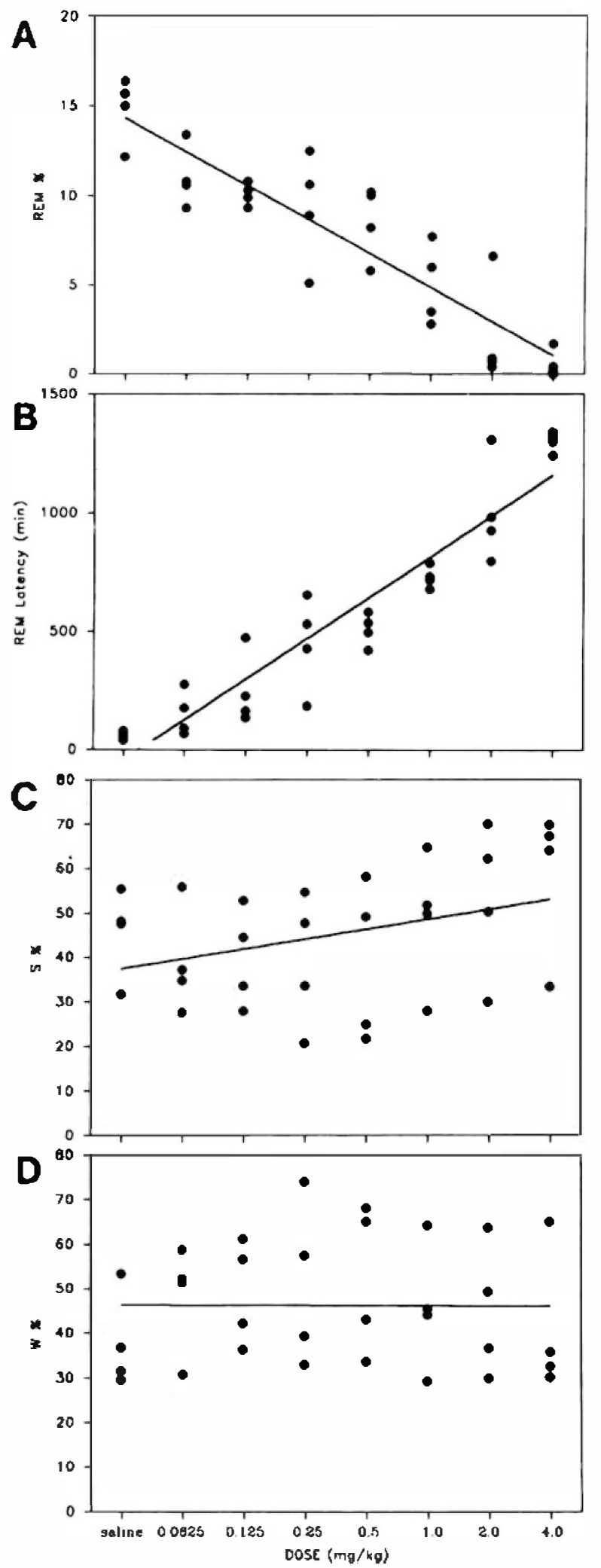

Figure 1. Dose effect of eltoprazine on REM\% (A), REM latency (B), S\% (C), and W\% (D). Data are plotted for each cat $(n=4)$ for each day of recording by dose. Note that REM\% decreased significantly $(p<0.001)$ in a dose-dependent manner. REM latency and S\% demonstrate a dose-dependent increase $(p<0.001)$. W\% does not vary by dose $(p>0.5)$.
Table 2. Polygraphic Parameters by Dose over 22 Hours

\begin{tabular}{lccc}
\hline $\begin{array}{l}\text { Dose } \\
\text { (mg/kg) }\end{array}$ & PGO & Delta & EMG \\
\hline Saline & $968(49)$ & $2345(74)$ & $1858(237)$ \\
0.0625 & $628(58)$ & $1714(124)$ & $2791(224)$ \\
0.125 & $568(78)$ & $1928(134)$ & $2515(259)$ \\
0.25 & $654(66)$ & $2008(127)$ & $2310(266)$ \\
0.5 & $422(65)$ & $2191(214)$ & $3035(304)$ \\
1.0 & $300(49)$ & $2342(265)$ & $3230(327)$ \\
2.0 & $18(7)$ & $3062(256)$ & $4216(397)$ \\
4.0 & $19(7)$ & $4465(207)$ & $5793(475)$ \\
\hline
\end{tabular}

Values expressed as mean (SEM) for counts/hr (PGO, delta) and amplitude units/hr (EMG).

\pm 237 amplitude units to a mean of $5793 \pm 475$ at 4 $\mathrm{mg} / \mathrm{kg}$ eltoprazine $(F=146.29, p<0.001$; Fig. 2 , bottom). As with delta wave activity, this effect on EMG amplitude varied significantly by hour $(F=3.34, p<$ $0.001)$, with most of the variability attributable to dose $(F=146.29)$.

\section{DISCUSSION}

The purpose of this study was to test the hypothesis that the $5-\mathrm{HT}_{1}$ agonist eltoprazine demonstrates dosedependent effects on REM sleep and REM sleep electrographic parameters. Our hypothesis was based on observations in which eltoprazine administered over five consecutive days totally suppressed REM sleep (Quattrochi et al. 1990), while total sleep time remained unchanged from control levels. Our data demonstrate that peripheral administration of eltoprazine suppresses REM sleep in a dose-dependent manner, with virtually total suppression of $\operatorname{REM}(0.4 \%)$ at the highest dose $(4 \mathrm{mg} / \mathrm{kg})$. Concurrent with this dose-dependent suppression of REM and PGO wave activity is a dosedependent increase in $S$ sleep, EEG synchrony, and mean EMG amplitude. No dose relationship was evident with W\%.

Our interpretation of these results is predicated on the assumption that parenterally administered eltoprazine stimulates $5-\mathrm{HT}_{1}$ receptors throughout the brain. The dose-dependent suppression of REM emphasizes the importance of endogenous serotonergic influences in controlling behavioral state and is consistent with the hypothesis that 5-HT neurons act to inhibit REM sleep but do not induce somnolence (Hobson and Storiate 1986). Suppression of PGO wave activity may be the result of serotonergic inhibition of the PGO wave trigger zone in the dorsolateral pons (Sakai 1980). This increase in S sleep and concomitant increase in EEG synchrony may be explained by either nonserotonergic processes (i. e., cholinergic antagonism) or by serotonergic modulation of thalamocortical or reticulothalamic pathways, resulting in a functional deaffer- 


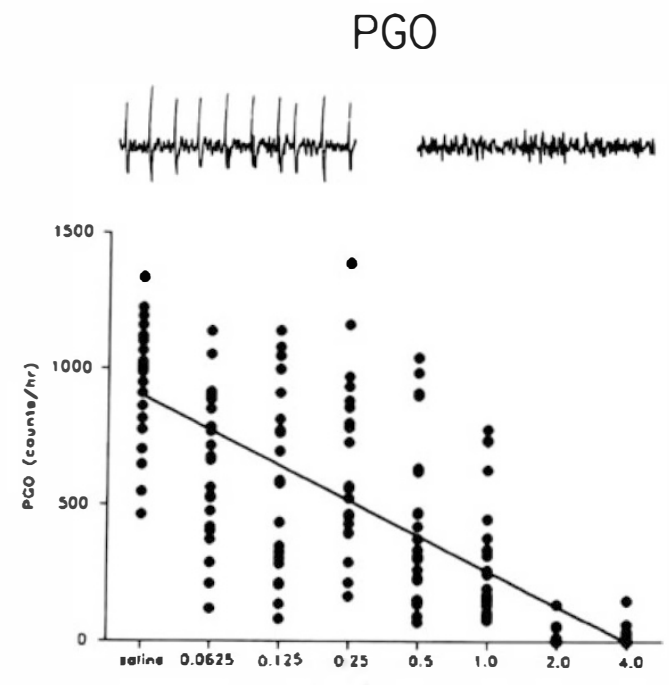

Delta
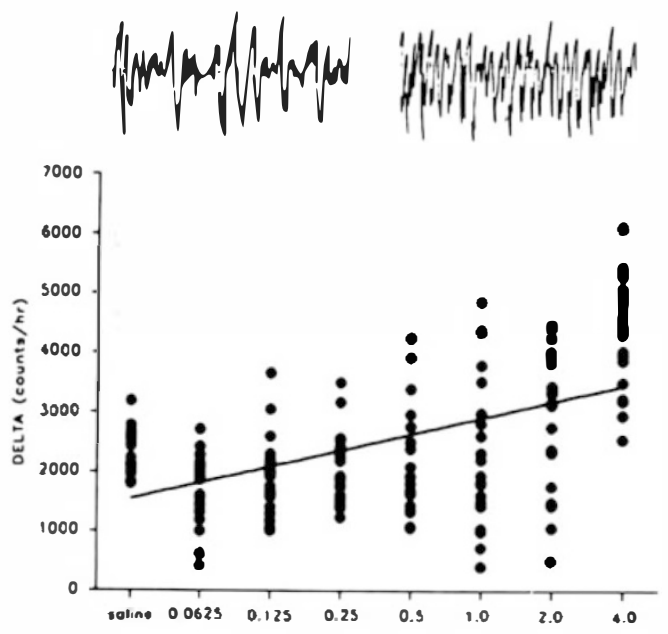

EMG

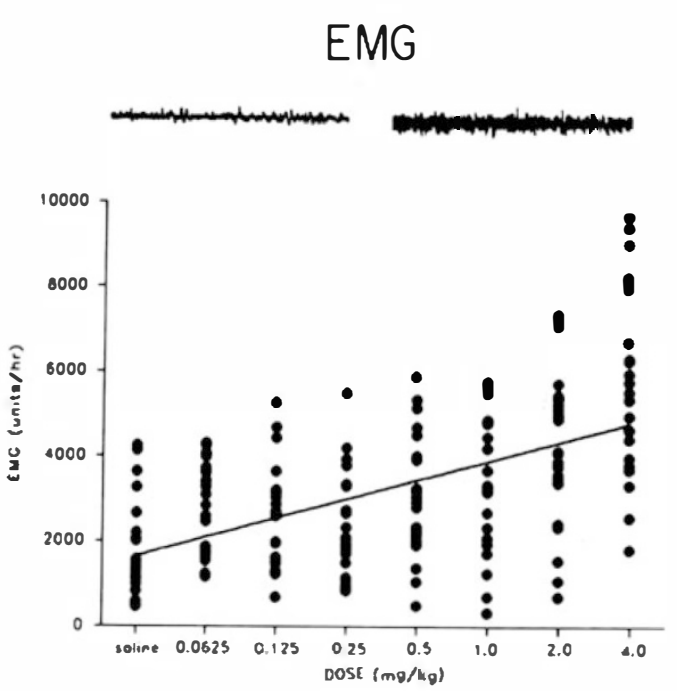

Figure 2. Dose effect of eltoprazine on waveband counts per hour for PGO, delta, and amplitude units per hour for EMG activity over each 22-hour recording period. Data points represent tallied counts per hour (converted from counts per minute) for each day of recording by dose. PGO activity (top) is entation of the cortex from thalamic influences (Hobson and Steriade 1986; Steriade et al. 1990b).

While increasing doses of eltoprazine increased S\%, a significant effect on delta wave counts was only seen at the highest $(4 \mathrm{mg} / \mathrm{kg})$ dose. For all other doses delta wave counts were close to control levels. This suggests that $4 \mathrm{mg} / \mathrm{kg}$ eltoprazine increases EEG synchrony far above control values, such that a rise in delta wave counts is also seen. However, this does not mean that eltoprazine has no influence on EEG synchrony at lower doses. The DAS used period-amplitude analysis to count all waves in the 1 to $4 \mathrm{~Hz}$ range as delta waves, regardless of amplitude. Qualitatively, we observed that lower doses of eltoprazine increase EEG synchrony and amplitude, along with $\mathrm{S} \%$. This qualitative change may not have been identified quantitatively by the DAS if the increased synchrony changed wave frequency from a high delta range ( 3 to $4 \mathrm{~Hz}$ ) to a low range ( 1 to $2 \mathrm{~Hz}$ ), such that the total number of counts per hour remained unchanged despite the increased number of epochs scored in an hour of S sleep. Spectral analysis would be useful in evaluating this issue.

Total time awake was unaffected by eltoprazine regardless of dose. This finding contrasts with reported increases in time awake following administration of the reuptake blockers zimeldine and alaproclate (Ursin et al. 1989) and other studies reporting sleep-disruptive effects of serotonergic agents (Lucki and Frazer 1982). The nonarousing effects of eltoprazine may be attributable to the intrinsic properties of the drug itself. However, we propose an alternate explanation: $5-\mathrm{HT}_{1}$ receptors may be important in modulating the REMNREM ultradian cycle but less important in modulating sleep-wake control.

Dose-response results indicate that PGO wave generation is the most sensitive electrographic parameter measured with regard to eltoprazine, being suppressed at doses unable to suppress REM. This suggests that PGO activity is strongly modulated by serotonergic influences. In physiologically normal REM, PGO phasic activity is generated by spontaneous bursting and discharge of PGO neurons located within the peribrachial pontine tegmentum (Sakai 1980). Lesioning of the raphe and administration of PCPA (RuchMonachon et al. 1976a), a blocker of 5-HT synthesis, are both reported to result in an increase in PGO waves. Serotonin agonists injected systemically are reported to result in a decrease of PGO frequency, indicating that

suppressed in a dose-dependent manner $(p<0.001)$. Delta wave counts (middle) and EMG amplitude (bottom) demonstrate a dose-dependent increase $(p<0.001)$. Typical waveband recordings of equal time calibration ( 8 seconds) for PGO, delta, and EMG activity (insets) are illustrated from saline control (left) and $4 \mathrm{mg} / \mathrm{kg}$ eltoprazine (right) experiments. 
the activity of 5-HT neurons inhibits PGO wave generation (Ruch-Monachon et al. 1976b). These findings together with our present results lead us to believe that 5-HT may now be confidently viewed as an inhibitory modulator of PGO activity. Furthermore, iontophoretic and raphe stimulation studies based on extracellular recordings in vivo have shown inhibitory effects of 5-HT on LGB neurons (Yoshida et al. 1984; Marks et al. 1987; Kayama et al. 1989). More recently, intracellular studies in vitro have shown that the response of thalamocortical relay LGB neurons to 5-HT is a slow depolarizing cation current, the response being blocked by methysergide, a 5-HT 1,2 antagonist (McCormick and Pape 1990). However, applications of the 5- $\mathrm{HT}_{1 \mathrm{~A}}$ agonist ipsapirone or the partial agonist 8-hydroxy-dipropylaminotetralin were without effect (McCormick and Pape 1990). PGO dose-related suppression by eltoprazine also supports the hypothesized PGO "gating" function (Simon et al. 1973; Trulson and Boys 1984) subserved by serotonergic neurons across behavioral states. There also may exist a "ceiling" dose for PGO suppression by eltoprazine of $2 \mathrm{mg} / \mathrm{kg}$, indicating that higher doses saturate the system. The virtual total suppression of PGO activity at doses of 2 and $4 \mathrm{mg} / \mathrm{kg}$ eltoprazine compared with the total suppression of REM only at the highest dose $(4.0 \mathrm{mg} / \mathrm{kg})$ suggests a possible differential sensitivity between PGO activity and other electrographic features of REM to 5-HT inhibitory influences.

Since the computer program that counted PGO waves preferentially detects larger amplitude singlespike type I waves over type II wave clusters (Mamelak et al. 1988), the total number of PGO waves tabulated actually underestimates the number of PGO waves that occurred. As REM\% and PGO wave activity decreased with increasing doses of eltoprazine, the actual number of $P G O$ waves decreased even more than was tabulated by the DAS, so that the actual dose dependency of PGO activity is almost certainly more significant than calculated.

We also observed a significant dose-dependent increase in EMG amplitude which may reflect an upregulation at the receptor level, such that increased levels of 5-HT result in enhanced EMG tonus. This finding is consistent with studies of 5-HT reuptake blockers (Sommerfelt and Ursin 1987) that typically demonstrate increased tonus associated with arousal, which we did not observe with eltoprazine. We suspect that circulating levels of eltoprazine result in a persistent inhibition of the pontine locus coeruleus alpha region (Sakai et al. 1981), thus maintaining EMG tonus at higher levels during all phases of sleep than in physiologically normal sleep.

In summary, effects of eltoprazine administration demonstrate dose-dependent suppression of REM sleep and PGO activity, increases in S sleep, and no effect on waking. Eltoprazine shifts the balance between
REM and S sleep but does not change the balance of sleep and waking. Eltoprazine is thus of potential use as a tool for investigating serotonergic-cholinergic interaction.

\section{ACKNOWLEDGMENTS}

This work was supported in part by Solvay Duphar B.V. and $\mathrm{NIH}$ grant $\mathrm{MH}-13923$.

We are indebted to J. Feldman, B. Banov, and D. Morley for their assistance throughout this study; to S. Datta, R. Stickgold, and J. Mos for discussions; and to S. Borack and R. Rubin for photographic assistance.

\section{REFERENCES}

Delorme F, Jeannerod M, Jouvet M (1965): Effets remarquables de la reserpine sur l'activité EEG phasique pontogeniculo-occipitale. C R Soc Biol (Paris) 159:900-904

Dement W, Hendricksen BL, Jacobs B, Mitler M (1973): Biogenic amines, phasic events, and behavior. In Bloom FE, Acheson G (eds), Pharmacology and the Future of Man: Brain, Nerves, and Synapses. New York, Krager, pp 74-89

Glennon R (1986): Central serotonin receptors as targets for drug research. J Med Chem 30:1-12

Hobson JA, Steriade M (1986): Neuronal basis of behavioral state control. In Mountcastle VB (ed), Handbook of Physiology. City, American Physiologic Society, Bethesda, MD pp 701-823

Jouvet M (1969): The role of monoamines and acetylcholinecontaining neurons in the regulation of the sleep-wake cycle. Science 163:32-41

Kayama Y, Shimada S, Hishikawa Y, Ogawa T (1989): Effects of stimulating the dorsal raphe nucleus of the rat on neuronal activity in the lateral geniculate nucleus. Brain Res 489:1-11

Lucki I, Frazer A (1982): Behavioraleffects of indole and piperazine type serotonin receptor agonists. Soc Neurosci Abstr 8:101

Mamelak A, Quattrochi J, Hobson JA (1988): A microcomputer-based system for automated EEG collection and scoring of behavioral state in cats. Brain Res Bull 21:843-849

Mamelak A, Quattrochi J, Hobson JA (1991): Automated staging of sleep using neural networks. Electroencephalogr Clin Neurophysiol 79:52-61

Marks G, Speciale S, Cobbey K, Roffwarg H(1987): Serotonergic inhibition of the dorsal lateral geniculate nucleus. Brain Res 418:76-84

McCormick DA, Pape HC (1990): Noradrenergic and serotonergic modulation of a hyperpolarization-activated cation current in thalamic relay neurons. J Physiol 431:319-342

Peroutka SJ (1988): 5-Hydroxytryptamine receptor subtypes: Molecular, biochemical, and physiological characterization. Trends Neurosci 11:496-500

Quattrochi J, Mamelak A, Madison R, Macklis J, Hobson JA (1989): Mapping neuronal inputs to REM sleep induc- 
tion sites with carbachol fluorescent microspheres. Science 245:984-986

Quattrochi J, Mamelak A, Binder D, Williams J, Hobson JA (1990): Dynamic suppression of REM sleep by parenteral administration of the serotonin $1_{\mathrm{ab}}$ agonist eltoprazine. Sleep Res 19:17

Raghoebar M, Olivier B, Rasmussen DL, Mos J (1990): Eltoprazine: A serenic compound. Drug Metababol Drug Interact 8:1-114

Ruch-Monachon MA, Jalfre M, Haefely W (1976a): Drugs and PGO waves in the lateral geniculate body of the curarized cat, II: PGO wave activity induced by RO4-1284 and by p-chlorophenylalanine (PCPA) as a basis for neuropharmacological studies. Arch Int Pharmacodyn Ther 219:251-268

Ruch-Monachon MA, Jalfre M, Haefely W (1976b): Drugs and PGO waves in the lateral geniculate body of the curarized cat, II: PGO wave activity and brain 5-hydroxytryptamine. Arch Int Pharmacodyn Ther 219:269-286

Sakai K (1980): Some anatomical and physiological properties of ponto-mesencephalic tegmental neurons. In Hobson JA, Brazier $M$ (eds), The Reticular Formation Revisited. New York, Raven Press, pp 427-447

Sakai K, Sastre JP, Kanamori N, Jouvet M(1981): State-specific neurons in the ponto-medullary reticular formation with special reference to the postural atonia during paradoxical sleep in the cat. In Pompeiano O, Ajmone-Marsan C (eds), Brain Mechanisms and Perceptual Awareness. New York, Raven Press, pp: 405-429

Simon R, Gershon M, Brooks D (1973): The role of the raphe nuclei in the regulation of pontogeniculooccipital wave activity. Brain Res 58:313-330

Sommerfelt L, Ursin R (1987): The effects of zimeldine and alaproclate combined with a small dose of 5-HTP on waking and sleep stages in cats. Behav Brain Res 24:1-10

Steriade M, Datta S, Pare D, Oakson G, Curro Dossi R (1990a): Neuronal activities in brain stem cholinergic nuclei related to tonic activation processes in thalamocortical systems. J Neurosci 10:2541-2559

Steriade M, Gloor P, Llinas RR, Lopes DA, Silva FH, Mesulam M-M (1990b): Basic mechanisms of cerebral rhythmic activities. Electroencephalogr Clin Neurophysiol 76:481-508

Trulson ME, Boys R (1984): Effects of chronic administration of d-amphetamine on PGO wave activity in the cat. Neuropharmacology 23:1151-1160

Ursin R, Bjorvatn B, Sommerfelt L, Underland G (1989): Increased waking as well as increased synchronization following administration of selective 5-HT uptake inhibitors to rats. Behav Brain Res 34:117-130

Vivaldi E, McCarley RW, Hobson JA (1980): Evocation of desynchronized sleep signs by chemical microstimulation of the pontine brain stem. In Hobson JA, Brazier M (eds), The Reticular Formation Revisited. New York, Raven Press, pp 513-529

Yoshida M, Masashi S, Takaori S (1984): Serotonin-mediated inhibition from dorsal raphe nucleus of neurons in the lateral geniculate and thalamic reticular nuclei. Brain Res 290:95-105 